\title{
Gastritis and gastroesophageal reflux disease are strongly associated with non-allergic nasal disorders
}

\author{
Eliana Finocchio ${ }^{1}$, Francesca Locatelli ${ }^{1}$, Francesca Sanna ${ }^{1}$, Roberta Vesentini ${ }^{1}$, Pierpaolo Marchetti ${ }^{1}$, \\ Gianluca Spiteri ${ }^{2}$, Leonardo Antonicelli ${ }^{3}$, Salvatore Battaglia', Roberto Bono ${ }^{5}$, Angelo Guido Corsico ${ }^{6}$, \\ Marcello Ferrari ${ }^{7}$, Nicola Murgia ${ }^{8}$, Pietro Pirina ${ }^{9}$, Mario Olivieri ${ }^{2}$ and Giuseppe Verlato ${ }^{1 *}$ (D)
}

\begin{abstract}
Background: Gastroesophageal reflux disease (GERD) has been reported to be significantly associated with chronic rhinosinusitis, but the strength of the association is still debated.

Aims: To evaluate the strength of the association between gastritis/GERD and non-allergic rhinitis (NAR)/allergic rhinitis (AR)/sinusitis.

Methods: We investigated 2887 subjects aged 20-84 years, who underwent a clinical visit in seven Italian centres (Ancona, Palermo, Pavia, Terni, Sassari, Torino, Verona) within the study on Gene Environment Interactions in Respiratory Diseases, a population-based multicase-control study between 2008 and 2014. Subjects were asked if they had doctor-diagnosed "gastritis or stomach ulcer (confirmed by gastroscopy)" or "gastroesophageal reflux disease, hiatal hernia or esophagitis". The association between NAR/AR/sinusitis and either gastritis or GERD was evaluated through relative risk ratios (RRR) by multinomial logistic regression.
\end{abstract}

Results: The prevalence of gastritis/GERD increased from subjects without nasal disturbances $(22.8 \%=323 / 1414)$ to subjects with AR $(25.8 \%=152 / 590)$ and further to subjects with NAR $(36.7 \%=69 / 188)$ or sinusitis $(39.9 \%=276 / 691)$. When adjusting for centre, sex, age, education level, BMl, smoking habits and alcohol intake, the combination of gastritis and GERD was associated with a four-fold increase in the risk of NAR (RRR $=3.80,95 \% \mathrm{Cl} 2.56-5.62)$ and sinusitis $(R R R=3.70,2.62-5.23)$ with respect to controls, and with a much smaller increase in the risk of $A R(R R R=1.79$, 1.37-2.35).

Conclusion: The study confirmed the association between gastritis/GERD and nasal disturbances, which is stronger for NAR and sinusitis than for AR.

Keywords: Gastritits, Gastroesophageal reflux disease, Allergic rhinitis, Non-allergic rhinitis, Sinusitis

*Correspondence: giuseppe.verlato@univr.it

1 Section of Epidemiology and Medical Statistics, Department

of Diagnostic and Public Health, University of Verona, Strada Le Grazie, 8,

37134 Verona, Italy

Full list of author information is available at the end of the article

\section{Background}

Rhinitis is a global common problem and is defined as the presence of at least one of the following: congestion, rhinorrhea, sneezing, nasal itching, and nasal obstruction. The two major classifications are allergic (AR) and nonallergic rhinitis (NAR) [1]. NAR occurs when obstruction and rhinorrhea are related to non-allergic, non-infectious triggers such as a change in the weather, exposure 
to caustic odors or cigarette smoke, barometric pressure differences, etc. [2]. The prevalence of AR in adults in Europe ranged from 17 to $28.5 \%$ [3], while NAR affects up to $30 \%$ of individuals in the Western population [4].

Gastro-esophageal reflux disease (GERD) is also a worldwide prevalent condition, which is on the rise in Europe and North America [5]. Hence also esophageal and extraesophageal diseases associated with GERD are expected to increase. Some of the well-established extraesophageal manifestations are reflux-induced cough, laryngitis, asthma and dental erosion. Other manifestations, such as sinusitis, pharyngitis, idiopathic pulmonary fibrosis, and recurrent otitis media, are proposed but not established as it is unclear whether GERD is a significant causal or exacerbating factor [6].

Since both chronic rhinosinusitis and GERD are highly prevalent, it is difficult to establish a direct relation between them, as they can easily coexist independently [7]. Moreover, while the association between GERD and nasal disorders gained support in children [8,9], in adults the evidence is still sparse. Several studies focused on the possible correlation of GERD and sinusitis [10-12], which have been reported to occur together more frequently than expected [13]. At first, several reviews did not find out a clear evidence-based relationship between Chronic rhinosinusitis and GERD [13-15]. However, in the last years the association between GERD and sinusitis gained support. Two European studies found that the SNOT (Sino-Nasal Outcome Test) score significantly increased among patients with GERD, suggesting a direct role of GERD in the development of chronic rhinosinusitis $[10,16]$. A large cohort study based on Taiwan Health Care Utilization database by Lin et al. [17] found that the risk of developing chronic rhinosinusitis was more than doubled in cases with newly diagnosed GERD with respect to controls matched for sex, age and comorbidities. In a population-based Brazilian survey the diagnosis of gastritis/ulcer/gastroesophageal reflux was associated with higher prevalence of rhinosinusitis symptoms in multivariable analysis [18]. An Italian study on a small series undergoing both nasal cytology and esophageal manometry and 24-h pH-impedance monitoring showed that NAR with neutrophils strongly correlated with higher acid exposure time and refluxes number [19]. On the basis of this accumulating evidence, the International Consensus Statement on Allergy and Rhinology: Rhinosinusitis [20] assigned grade B evidence to support the association between chronic rhinosinusitis and GERD, although causation could not be clearly demonstrated.

The association between GERD and AR is more questioned. The recent International Consensus Statement on Allergic Rhinitis does not even mention GERD at all as a potential risk factor [21]. The situation is complex, as several studies which found an association between GERD and nasal disorders did not distinguish between NAR and AR [22].

Since nasal disorders are highly prevalent diseases that can have a deep impact on individual life and healthcare system, it is important to identify causative and triggering factors, and their comorbidities. The present study aimed to investigate the relation between gastritis/GERD and allergic and non-allergic rhinitis in a large population-based case-control study.

\section{Methods \\ Study design}

The study was performed in the frame of the GEIRD (Gene-Environment Interactions in Respiratory Diseases) study, a multicase-control study on respiratory health, involving seven Italian centers, three located in Northern Italy (Verona, Pavia, Turin), two in Central Italy (Ancona, Terni) and two in the major islands (Sassari in Sardinia and Palermo in Sicily) [23]. The study comprised a screening phase and a clinical phase. In the screening phase a screening questionnaire was mailed to random samples from the general population aged 20-84 years, while in the clinical phase subjects reporting symptoms suggestive of chronic bronchitis, asthma or rhinitis, as well as a sample of subjects without respiratory symptoms, were invited to a local Respiratory/Allergy Unit, in order to undergo interviews and clinical tests. In particular, participating subjects were administered a modified version of the ECRHS (European Community Respiratory Health Survey) clinical questionnaire, including detailed questions on socio-demographic characteristics, smoking habits and other lifestyle factors, respiratory symptoms and other disturbances, drug consumption [23; available at www.geird.org]. In each center, the GEIRD study was approved by the local ethics committee and written consent was obtained from each participant.

Fifty-nine percent $(17,972 / 30,349)$ of selected subjects answered the screening questionnaire, while 2,945 subjects out of 7,739 participated in the clinical visit between 2008 and 2014, yielding a participation rate of $40.1 \%$.

\section{Nasal disorders}

Subjects were classified as having "rhinitis" if they answered affirmatively to at least one of the following questions: "Do you have any nasal allergies including hay fever?", "During your lifetime have you ever had any nasal allergies including hay fever?", "Have you ever had a problem with sneezing, or a runny or a blocked nose when you did not have a cold or the flu?". Rhinitis was further classified as allergic rhinitis (AR) and non-allergic rhinitis (NAR), according to the presence or absence of 
atopy. Subjects were also asked whether they ever suffered from nasal polyps.

Treatments for nasal disorders were assessed by the following questions "Have you used any of the following nasal medicines (e.g. nasal sprays, inhaled powders or drops) for the treatment of your nasal disorders?" and "Have you used any of the following pills, capsules, or tablets for the treatment of your nasal disorder?".

\section{Other respiratory disorders}

Asthma was deemed present when the subject reported physician-diagnosed asthma. The disease was further classified in: current asthma if the subject took any medicine for asthma or had had an attack of asthma or reported any asthma-like symptom (wheezing, chest tightness or shortness of breath) in the previous 12 months; past asthma otherwise.

Chronic cough and phlegm was defined by a positive answer to the question: "Have you had coughing and phlegm on most days for a minimum of 3 months a year and for at least 2 successive years?". Doctor-diagnosed chronic bronchitis was defined by an adfirmative answer to the question: "Have you ever been told by a doctor that you have or had chronic bronchitis, chronic obstructive pulmonary disease (COPD) or emphysema?".

\begin{abstract}
Atopy
Atopy was established by a positive skin prick test in which the following panel of allergens were used: Cupressus arizonica, Dermatophagoides pteronyssinus, Artemisia vulgaris, Dermatophagoides farinae, Ambrosia artemisifolia, Alternaria tenuis, Parietaria judaica, dog dandruff, Corylus avellana, cat, Olea europea, Betula verrucosa, Cladosporium herbarum, and Phleum pratense. The result was considered positive if, after twenty minutes, the average wheal diameter was $3 \mathrm{~mm}$ greater than the negative control.
\end{abstract}

\section{Gastritis/gastroesophageal reflux}

Subjects were classified as having gastritis if they answered positively to the question "Has a doctor told you having or have had gastritis or stomach ulcer (confirmed by a gastroscopy)?" Similarly, subjects were considered having gastroesophageal reflux disease (GERD) if they answered affirmatively to the question "Has a doctor told you having or have had gastroesophageal reflux disease, hiatal hernia or esophagitis?".

\section{Lifestyle factors}

Subjects were classified as normal weight $(\mathrm{BMI}<25 \mathrm{~kg} /$ $\left.\mathrm{m}^{2}\right)$, overweight $\left(25 \leq \mathrm{BMI}<30 \mathrm{~kg} / \mathrm{m}^{2}\right)$, or obese $\left(B M I \geq 30 \mathrm{~kg} / \mathrm{m}^{2}\right)$. They were considered active when reporting to exercise for at least $1 \mathrm{~h}$ getting out of breath or sweating with a frequency of at least 2-3 times a week.

With regard to smoking habits, subjects were classified as (1) current smokers, if they reported to have smoked at least one cigarette per day or one cigar a week for as long as one year, and also in the last month; (2) ex-smokers if they had smoked the same minimum amount previously reported, but had stopped smoking for at least one month before the interview; (3) never smokers otherwise. As regards alcohol consumptions, subjects were classified as drinkers and nondrinkers.

\section{Statistical analyses}

Significance of the association between AR/NAR/sinusitis and potential risk factors was evaluated by Fisher's exact test or Chi-squared test. The same statistical tests were used to evaluate the association between gastritis/ gastroesophageal reflux and other risk factors.

Multivariable analysis was accomplished by a multinomial logistic regression model [24], where the response variable was nasal symptoms: $0=$ no symptom (base outcome), $1=$ allergic rhinitis, $2=$ non-allergic rhinitis, $3=$ sinusitis. Gastroesophageal reflux (none/gastritis/ reflux/both gastritis and reflux) was the explanatory variable, while sex, age (per 10 year increase), age at completing full-time education $(<18,18-21, \geq 22$ years), BMI $\left(<25,25-29.9, \geq 30 \mathrm{~kg} / \mathrm{m}^{2}\right)$, smoking habits (never smoker, past smoker, current smoker), alcohol intake (nondrinker, drinker), were the potential confounders. Results were synthesized through the relative risk ratios (RRR), adjusting standard errors for intra center correlation. Analyses were performed with STATA statistical software, release 14 (StataCorp, College Station, TX, USA) and statistical significance was set at $\mathrm{p}<0.05$.

\section{Results \\ Description of controls and cases of AR/NAR/sinusitis, as a function of main risk factors}

2887 subjects participated in the clinical visit and they had a mean age (SD) of 50.1 (13.2) years. Cases of AR and sinusitis were younger (mean age $\pm \mathrm{SD}=46.0 \pm 11.8$ and $48.7 \pm 11.9$ years, respectively) than controls and cases of NAR ( $52 \pm 13.7$ and $54.6 \pm 14$ years, respectively) $(p<0.001)$. Controls and cases of NAR had a lower level of education and physical activity, a higher prevalence of obesity than cases of AR and sinusitis. Atopy, which was used to define NAR and AR, had a prevalence of $27 \%$ in controls and $58 \%$ in cases of sinusitis. Nasal polyps were rare in controls and cases of NAR, and more common in cases of AR and sinusitis. Use of antihistamines and steroids was frequent among cases of $\mathrm{AR}$, and rare among cases of NAR, while the use of vasoconstrictors was similar in the two groups. Sex, smoking habits and alcohol 
intake did not significantly differ between cases and controls (Table 1).

\section{Description of controls and cases of gastroesophageal disorders, as a function of main risk factors}

People with gastritis and/or gastroesophageal reflux were older and had attained a lower education level than people without these disorders (Table 2). Women more frequently reported gastritis and gastroesophageal reflux than men. Gastritis and gastroesophageal reflux were more common, respectively, in current smokers and overweight people.

Atopy and nasal polyps, the level of physical activity and alcohol intake did not significantly change as a function of gastritis/gastroesophageal reflux.

\section{Description of controls and cases of AR/NAR/Sinusitis, as a function of gastroesophageal disorders}

Gastritis/gastroesophageal reflux were strongly associated with nasal disorders. The prevalence of gastritis/ reflux was $5.9 \%$ in controls, it slightly increased to $7.5 \%$ in cases of allergic rhinitis and further to $18.1 \%$ and $15.8 \%$ in cases of NAR and sinusitis, respectively (Table 3).

\section{Multivariable analyses}

The combination of gastritis and GERD was associated with a four-fold increase in the risk of NAR $(R R R=3.80$, 95\% CI 2.56-5.62) and sinusitis (RRR $=3.70,2.62-5.23$ ) with respect to people without these disorders, and with a much smaller increase in the risk of $A R(R R R=1.79$, 1.37-2.35). The risk of nasal disorders was significanlty increased, although to a smaller extent, in subjects reporting gastritis alone, while GERD was significantly associated with sinusitis but not with either NAR or AR (Fig. 1).

A regards the other factors, the risk of NAR was higher in women than men $(R R R=1.28,1.19-1.37)$. Moreover, the risk of $A R$ and sinusitis decreased with advancing age (RRR per 10-year increase $=0.70,0.63-0.79$ and $0.79,0.66-0.95$, respectively). The risk of NAR was higher in current smokers than never smokers $(R R R=1.48$, 1.16-1.89), and in people with medium than low education $(R R R=1.12,1.00-1.26)$. With respect to normoweight, obesity was associated with a lower risk of $\mathrm{AR}(\mathrm{RRR}=0.75,0.58-0.97)$ and sinusitis $(\mathrm{RRR}=0.79$, $0.65-0.95)$. The risk of sinusitis was slightly higher in past smokers than never smokers $(R R R=1.18,1.01-1.38)$ and in alcohol drinkers than non-drinkers $(R R R=1.23$, 1.02-1.47).

\section{Discussion}

The main findings of the present study are:
1. Gastritis and GERD were strongly associated with non-allergic nasal diseases (NAR and sinusitis) and, to a much smaller extent, to allergic rhinitis, both in univariable and multivariable analysis.

2. The association was rather strong for the combination of gastritis and GERD, and rather weak for gastritis alone, and nearly absent for GERD alone. Subjects self-reporting both gastrointestinal diseases had probably a more severe condition than the other subjects.

3. Nasal polyps, while nearly absent in controls and cases of NAR, were found in $5 \%$ of cases of AR and $8 \%$ of cases of sinusitis. Their prevalence was not significantly affected by gastritis/GERD.

4. The risk of AR and sinusitis decreased with advancing age and in obese people. As regards lifestyle factors, NAR was associated with current smoking, and sinusitis with alcohol consumption.

The present multicase-control study showed that upper gastrointestinal disorders were strongly associated with non-allergic nasal disorders: the prevalence of gastritis and/or GERD was $22.8 \%$ in controls, only slightly increased in cases of AR (25.8\%), and peaked up in cases of non-allergic nasal disorders, such as NAR (36.7\%) and sinusitis (39.9\%). These findings were confirmed in multivariable analysis, where the combination of gastritis and GERD was associated with a nearly four-fold increase in the risk of NAR and sinusitis, while the risk of AR was less than doubled.

These findings are in agreement with the current literature. As already mentioned, the association between chronic rhinosinusitis and GERD has been acknowledged by the International Consensus Statement on Allergy and Rhinology: Rhinosinusitis [20], although with moderate evidence. On the other hand, the association between AR and GERD is not even mentioned by the recent International Consensus Statement on Allergic Rhinitis [21]. A recent study supported GERD involvement in the development of NAR, since patients with NAR displayed a high level of pepsin in saliva samples, especially in the postprandial period, compared to healthy controls [4].

Nasal polyps were not significantly related to gastritis/ GERD in the present study. According to Lin et al. [17] the association between GERD and chronic rhinosinusitis was stronger in subjects without than with nasal polyps.

An interesting approach to the relation between GERD and nasal disorders consists in verifying whether treatment of GERD could improve nasal symptoms especially in chronic rhinosinusitis refractory to clinical or surgical treatment. However, a recent review assessed the effect of treatment with proton pump inhibitors (PPIs) on chronic 
Table 1 Number and percent of controls, cases of non-allergic rhinitis (NAR), allergic rhinitis (AR) and sinusitis as a function of main socio-demographic, lifestyle, and clinical characteristics

\begin{tabular}{|c|c|c|c|c|c|}
\hline & $\begin{array}{l}\text { Controls }(n=1416) \\
n(\%)\end{array}$ & $\begin{array}{l}\text { AR }(n=592) \\
n(\%)\end{array}$ & $\begin{array}{l}\text { NAR }(n=188) \\
n(\%)\end{array}$ & $\begin{array}{l}\text { Sinusitis }(\mathrm{n}=691) \\
\mathrm{n}(\%)\end{array}$ & $p$ value \\
\hline Sex & & & & & 0.068 \\
\hline Male & $729(51.5)$ & $317(53.5)$ & $87(46.3)$ & $326(47.2)$ & \\
\hline Female & $687(48.5)$ & $275(46.5)$ & $101(53.7)$ & $365(52.8)$ & \\
\hline Age (years) & & & & & $<0.001$ \\
\hline $20-34$ & $144(10.2)$ & $95(16.1)$ & $12(6.4)$ & $70(10.1)$ & \\
\hline $35-44$ & $339(23.9)$ & $194(32.8)$ & $34(18.1)$ & $218(31.6)$ & \\
\hline $45-54$ & $388(27.4)$ & $191(32.3)$ & $61(32.5)$ & $218(31.6)$ & \\
\hline $55-64$ & $254(17.9)$ & $72(12.2)$ & $36(19.2)$ & $119(17.2)$ & \\
\hline$\geq 65$ & $291(20.6)$ & $40(6.8)$ & $45(23.9)$ & $66(9.6)$ & \\
\hline Time at stopping education (years) & & & & & $<0.001$ \\
\hline$<18$ & $465(33.1)$ & $141(24)$ & $64(34.8)$ & $190(27.7)$ & \\
\hline $18-21$ & $498(35.5)$ & $222(37.8)$ & $68(37)$ & $267(38.9)$ & \\
\hline$\geq 22$ & $440(31.4)$ & $225(38.3)$ & $52(28.3)$ & $228(33.3)$ & \\
\hline $\mathrm{BMI}\left(\mathrm{kg} / \mathrm{m}^{2}\right)$ & & & & & 0.030 \\
\hline$<25$ & $681(49.9)$ & $328(56.6)$ & $94(50.5)$ & $355(53.4)$ & \\
\hline $25-29$ & $475(34.8)$ & $187(32.2)$ & $62(33.3)$ & $236(35.5)$ & \\
\hline$\geq 30$ & $208(15.3)$ & $65(11.2)$ & $30(16.1)$ & $74(11.1)$ & \\
\hline Physical activity (times/week) & & & & & 0.038 \\
\hline$<2-3$ times & $983(69.9)$ & $379(64.6)$ & $138(74.2)$ & $467(67.9)$ & \\
\hline$\geq 2-3$ times & $423(30.1)$ & $208(35.4)$ & $48(25.8)$ & $221(32.1)$ & \\
\hline Smoking habits & & & & & 0.577 \\
\hline No smoker & $684(49.4)$ & $305(52.6)$ & $81(43.8)$ & $333(49.3)$ & \\
\hline Ex smoker & $411(29.7)$ & $158(27.2)$ & $60(32.4)$ & $200(29.6)$ & \\
\hline Current smoker & $290(20.9)$ & $117(20.2)$ & $44(23.8)$ & $142(21.0)$ & \\
\hline Alcohol intake (No/Yes) & & & & & 0.158 \\
\hline No drinker & $875(62.3)$ & $349(59.4)$ & $121(64.7)$ & $399(58.1)$ & \\
\hline Drinker & $529(37.7)$ & $239(40.6)$ & $66(35.3)$ & $288(41.9)$ & \\
\hline Atopy & & & & & $<0.001^{*}$ \\
\hline No & $931(72.7)$ & - & $188(100.0)$ & $268(41.9)$ & \\
\hline Yes & $349(27.3)$ & $592(100.0)$ & - & $372(58.1)$ & \\
\hline Nasal polyps (ever) & & & & & $<0.001$ \\
\hline No & $1396(98.8)$ & $564(95.4)$ & $185(98.4)$ & $632(91.7)$ & \\
\hline Yes & $17(1.2)$ & $27(4.6)$ & $3(1.6)$ & $57(8.3)$ & \\
\hline Asthma & & & & & $<0.001$ \\
\hline No & $1807(85.25)$ & $225(40.47)$ & $109(72.67)$ & $328(52.82)$ & \\
\hline Yes & 107 (8.39) & $238(42.81)$ & $29(19.33)$ & $213(34.30)$ & \\
\hline Past & $81(6.35)$ & $93(16.73)$ & $12(8.00)$ & $80(12.88)$ & \\
\hline Chronic chough and phlegm & & & & & $<0.001$ \\
\hline No & $1.338(95.1)$ & $524(88.81)$ & $154(83.24)$ & 588 (85.59) & \\
\hline Yes & $69(4.9)$ & $66(11.19)$ & $31(16.76)$ & $99(14.41)$ & \\
\hline Doctor-diagnosed chronic bronchitis & & & & & 0.562 \\
\hline No & $1236(97.78)$ & $521(97.38)$ & 156 (96.89) & $587(96.71)$ & \\
\hline Yes & $28(2.22)$ & $14(2.62)$ & $5(3.11)$ & $20(3.29)$ & \\
\hline Steroids (ever) & & & & & $<0.001$ \\
\hline No & 1302 (98.6) & $422(80.8)$ & $160(92.5)$ & $491(79.1)$ & \\
\hline Yes & $18(1.4)$ & $100(19.2)$ & $13(7.5)$ & $130(20.9)$ & \\
\hline Vasoconstrictors (ever) & & & & & $<0.001$ \\
\hline No & $1274(96.4)$ & $394(75.3)$ & $142(81.6)$ & $486(77.8)$ & \\
\hline Yes & $48(3.6)$ & $129(24.7)$ & $32(18.4)$ & $139(22.2)$ & \\
\hline Antihistamines (ever) & & & & & $<0.001$ \\
\hline No & $1320(99.7)$ & $362(69)$ & $162(93.1)$ & $495(78.8)$ & \\
\hline Yes & $4(0.3)$ & $163(31.1)$ & $12(6.9)$ & $133(21.2)$ & \\
\hline
\end{tabular}


Table 1 (continued)

Significance of differences was computed by Fisher's exact test or Chi-square test

* Computed only on controls and people with sinusitis

Table 2 Number (percentage) of controls, cases of gastritis and gastroesophageal reflux, isolated or combined, as a function of main socio-demographic, lifestyle and clinical characteristics

\begin{tabular}{|c|c|c|c|c|c|}
\hline & $\begin{array}{l}\text { No gastritis/reflux } \\
(n=2128)\end{array}$ & Gastritis only ( $n=264)$ & Reflux only $(n=310)$ & $\begin{array}{l}\text { Both Gastritis } \\
\text { and Reflux } \\
(n=278)\end{array}$ & $p$ value \\
\hline Sex & & & & & 0.034 \\
\hline Male & $1101(51.7)$ & $131(49.6)$ & $159(51.3)$ & $118(42.5)$ & \\
\hline Female & $1027(48.3)$ & $133(50.4)$ & $151(48.7)$ & $160(57.6)$ & \\
\hline Age (years) & & & & & $<0.001$ \\
\hline $20-34$ & $282(13.3)$ & $11(4.2)$ & $19(6.1)$ & $15(5.4)$ & \\
\hline $35-44$ & $601(28.2)$ & $61(23.1)$ & $78(25.2)$ & $70(25.2)$ & \\
\hline $45-54$ & $648(30.5)$ & $68(25.8)$ & $87(28.1)$ & $81(29.1)$ & \\
\hline $55-64$ & $323(15.2)$ & $46(17.4)$ & $61(19.7)$ & $63(22.7)$ & \\
\hline$>65$ & $274(12.9)$ & $78(29.6)$ & $65(21.0)$ & $49(17.6)$ & \\
\hline Time at stopping education (years) & & & & & $<0.001$ \\
\hline$<18$ & $578(27.4)$ & $111(42.4)$ & $93(30.4)$ & $103(37.5)$ & \\
\hline $18-21$ & $806(38.2)$ & $73(27.9)$ & $111(36.3)$ & $99(36.0)$ & \\
\hline$\geq 22$ & $727(34.4)$ & $78(29.8)$ & $102(33.3)$ & $73(26.5)$ & \\
\hline BMI & & & & & 0.021 \\
\hline$<25$ & $1104(53.8)$ & $137(53.5)$ & $130(43.6)$ & $126(46.8)$ & \\
\hline $25-29$ & $679(33.1)$ & $83(32.4)$ & $125(42.0)$ & $102(37.9)$ & \\
\hline$\geq 30$ & $271(13.2)$ & $36(14.1)$ & $43(14.4)$ & $41(15.2)$ & \\
\hline Physical activity (hours/week) & & & & & 0.112 \\
\hline$<2 / 3$ & $1428(67.7)$ & $194(74.0)$ & $217(70.5)$ & $198(71.5)$ & \\
\hline$\geq 2 / 3$ & $683(32.4)$ & $68(26.0)$ & $91(29.5)$ & $79(28.5)$ & \\
\hline Smoking habits & & & & & 0.006 \\
\hline No smoker & $1059(50.9)$ & $103(40.4)$ & $154(50.2)$ & $128(47.4)$ & \\
\hline Ex smoker & $588(28.2)$ & $92(36.1)$ & $105(34.2)$ & $79(29.3)$ & \\
\hline Current smoker & $435(20.9)$ & $60(23.5)$ & $48(15.6)$ & $63(23.3)$ & \\
\hline Alcohol intake (no/yes) & & & & & 0.793 \\
\hline No drinker & $1284(60.9)$ & $165(63.2)$ & $182(59.1)$ & $168(60.4)$ & \\
\hline Drinker & $826(39.1)$ & $96(36.8)$ & $126(40.9)$ & $110(39.6)$ & \\
\hline Atopy & & & & & 0.485 \\
\hline No & $1009(51.1)$ & $123(53.0)$ & $131(49.6)$ & $143(55.6)$ & \\
\hline Yes & $964(48.9)$ & $109(47.0)$ & $133(50.4)$ & $114(44.4)$ & \\
\hline Nasal polyps & & & & & 0.238 \\
\hline No & 2049 (96.6) & $253(96.2)$ & $291(94.5)$ & 271 (97.5) & \\
\hline Yes & $73(3.4)$ & $10(3.8)$ & $17(5.5)$ & $7(2.5)$ & \\
\hline
\end{tabular}

Significance of differences was evaluated by Fisher's exact test or Chi-square test

rhinosinusitis symptoms in four longitudinal studies, and found conflicting results [25].
Pathophysiological mechanisms

Several mechanisms have been proposed to explain the relation between acid reflux and chronic rhinosinusitis. Subjects with chronic rhinosinusitis have been shown to have more proximal gastroesophageal reflux than healthy controls [26]. 
Table 3 Prevalence of gastroesophageal disorders (gastritis/GERD) in controls, rhinitis, allergic rhinitis and sinusitis subjects

\begin{tabular}{lllll}
\hline & $\begin{array}{l}\text { Controls }(\mathbf{n = 1 4 1 4 )} \\
\mathbf{n}(\%)\end{array}$ & $\begin{array}{l}\mathbf{A R}(\mathbf{n}=\mathbf{5 9 0}) \\
\mathbf{n}(\%)\end{array}$ & $\begin{array}{l}\text { NAR }(\mathbf{n}=\mathbf{1 8 8}) \\
\mathbf{n}(\%)\end{array}$ & $\begin{array}{l}\text { Sinusitis }(\mathbf{n}=\mathbf{6 9 1}) \\
\mathbf{n}(\%)\end{array}$ \\
\hline Gastritis/reflux & & & & $\boldsymbol{p}$ value \\
No gastritis/GERD & $1091(77.2)$ & $438(74.2)$ & $119(63.3)$ & $415(60.1)$ \\
Gastritis/GERD & $323(22.8)$ & $152(25.8)$ & $69(36.7)$ & $276(39.9)$ \\
Gastritis only & $108(7.6)$ & $43(7.3)$ & $21(11.2)$ & $81(11.7)$ \\
GERD Only & $132(9.3)$ & $65(11)$ & $14(7.5)$ & $86(12.5)$ \\
GERD and Gastritis & $83(5.9)$ & $44(7.5)$ & $34(18.1)$ & $109(15.8)$ \\
\hline
\end{tabular}

$p$ values were computed by Pearson's Chi-square test

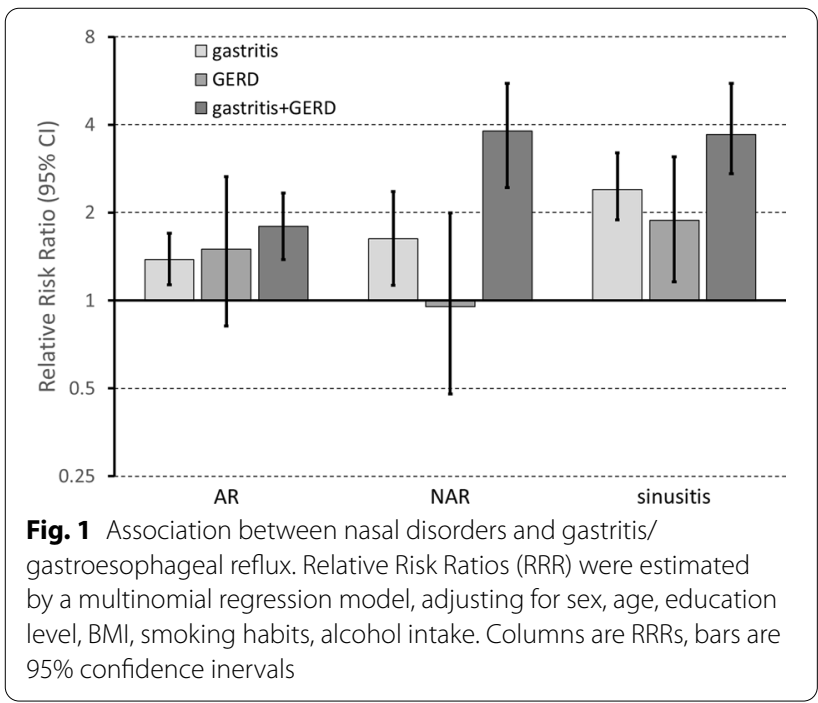

First of all, gastric acid exposure may exacerbate inflammation within the mucosa of the upper airways and sinuses and impair mucociliary motility, causing obstruction of sinus ostia and favouring recurrent infections [27-29].

A second mechanism could be vagally-mediated neuroinflammatory changes [11]. Autonomic dysfunction can lead to reflex sinonasal swelling and inflammation, leading to blockage of the ostia. Wong et al. [30] gave experimental support to this hypothesis, showing that infusion of saline with hydrochloric acid in the lower esophagus increased nasal mucus production and nasal symptom score.

Also a role of Helicobacter pylori (H. pylori) has been proposed, as the microorganism has been detected not only in the stomach but also in oral and nasal mucosa [31]. In particular, H. pylori has been found in nasal polyps but not in control tissue [32], and in patients who have both GERD and chronic rhinosinusitis [33]. Moreover, H. Pylori causes not only gastritis but also systemic inflammation, which can involve also the nasal mucosa.

\section{Strengths and limitations}

The present study has several strengths. It involved seven centres scattered from Northern to Southern Italy, 1,471 cases of nasal disorders and 1,416 controls, and information was collected by standardized methods (questionnaire and skin prick test).

However, some limitations should be acknowledged. First of all, the cross-sectional design did not allow to properly infer the cause-effect relationship between GERD/gastritis and NAR. Indeed, to prove such a cause effect relation, longitudinal studies with an adequate number of patients are needed. Second, while information on nasal disorders was based on questionnaire and objective measurement (skin prick test), information on gastritis and GERD was exclusively derived by questionnaire. Gastritis alone apparently had larger effects on AR and NAR than GERD alone. It should be reminded that the question on gastritis was probably more reliable as it involved not only medical diagnosis but also objective assessment (gastroscopy), while the question on GERD put together different diseases (GERD, hiatal hernia, or esophagitis) and did not refer to instrumentally confirmed diagnosis. Moreover, subjects who reported both gastritis and GERD probably had a more clear-cut gastrointestinal disease than those reporting only one disease. In turn, improvement in exposure definition allowed to better assess association with nasal disorders.

\section{Conclusions}

According to the present study, gastritis and GERD were strongly associated with nasal disorders, in particular non-allergic ones (NAR and sinusitis). On the other hand AR, which was defined by symptoms and positive skin prick test, has an IgE-mediated pathogenesis and is only mildly affected by irritant substances, such as acid reflux. 
Nevertheless, to prove a causal effect relationship, prospective studies with a significant number of patients are needed. In particular randomized controlled trials should verify whether reflux treatment also improve concomitant nasal disorders.

\section{Abbreviations}

GERD: Gastroesophageal reflux disease; NAR: Non-allergic rhinitis; AR: Allergic rhinitis; GEIRD: Gene-Environment Interactions in Respiratory Diseases; ECRHS: European Community Respiratory Health Survey.

\section{Acknowledgements}

Not Applicable

\section{Authors' contributions}

EF, MO, GV devised the present study. RV, PM, FL prepared the database. EF, $F L, F S, G V$ performed statistical analyses. $L A, S B, R B, A C, M F, N M, P P, M O, G V$ found resources. EF, FL, FS, GS, MO, GV drafted the preliminary manuscript. All authors read and approved the final manuscript.

\section{Funding}

The GEIRD project was funded by Cariverona Foundation (Verona, Italy), Italian Ministry of Education, Universities and Research (MIUR), Italian Ministry of Health (Ministero della Salute), Chiesi Farmaceutici S.p.A. The funding sources had no involvement in the study design, collection, analysis and interpretation of data, writing of the report or decision to submit the paper for publication.

\section{Availability of data and materials}

The datasets used and/or analysed during the current study are available from the corresponding author on reasonable request.

\section{Ethics approval and consent to participate}

Ethics approval was obtained in each centre involved in the GEIRD study from the appropriate ethics committee (Comitato Etico dell'Azienda OspedalieroUniversitaria Ospedali Riuniti di Ancona; Comitato Etico dell'Azienda Ospedaliera Ospedali Riuniti Villa Sofia Cervello di Palermo; Comitato di Bioetica della Fondazione IRCCS Policlinico San Matteo di Pavia; Comitato Etico delle Aziende Sanitarie dell'Umbria di Perugia; Comitato di Bioetica dell'Azienda Sanitaria Locale di Sassari; Comitato Etico dell'Azienda Sanitaria Locale TO/2 di Torino; Comitato Etico per la Sperimentazione dell'Azienda Ospedaliera Istituti Ospitalieri di Verona). Information on the purpose of the survey and participants' rights according to then current Italian law (Decreto Legislativo 30 giugno $2003, n$. 196) were enclosed to the questionnaire administered by mail. Individuals were free to answer or not answer the questionnaire, as denoted by the non-negligible nonresponse rate. Hence, consent to participate was implied by the answer to the questionnaire, and this form of consent was approved by the local Ethics Committee.

\section{Consent for publication}

Not applicable.

\section{Competing interests}

G. Verlato is Section Editor of BMC Pulmonary Medicine, for the Section Epidemiology and Public Health. G. Verlato received financial support from BioMed Central to participate in the 2014 and 2015 Congresses of the European Respiratory Society. All remaining authors declare that they have no competing interests.

\section{Author details}

1 Section of Epidemiology and Medical Statistics, Department of Diagnostic and Public Health, University of Verona, Strada Le Grazie, 8, 37134 Verona Italy. ${ }^{2}$ Unit of Occupational Medicine, Department of Diagnostics and Public Health, University of Verona, P.le L.A. Scuro 10, 37134 Verona, Italy. ${ }^{3}$ Department of Internal Medicine Ospedali Riuniti Ancona, Via Conca, 71, 60126 Ancona, Italy. ${ }^{4}$ University of Palermo, Piazza Marina, 61, 90133 Palermo, Italy. ${ }^{5}$ Department of Public Health and Pediatrics, University of Torino, Via Santena 5 bis, 10126 Torino, Italy. ${ }^{6}$ Department of Internal Medicine and Medical Therapy, University of Pavia, Palazzo Botta, 10, 27100 Pavia, Italy. ${ }^{7}$ Unit of Respiratory Diseases, Department of Medicine, University of Verona, P.le L.A. Scuro 10, 37134 Verona, Italy. ${ }^{8}$ Section of Occupational Medicine, Respiratory Diseases and Toxicology, University of Perugia, Piazza dell'Università, 1, 06123 Perugia, Italy. ${ }^{9}$ Department of Clinical, Surgical and Experimental Sciences, University of Sassari, Piazza Università, 21, 07100 Sassari, Italy.

Received: 14 July 2020 Accepted: 30 November 2020

Published online: 08 February 2021

\section{References}

1. Bachert C, van Cauwenberge P, Olbrecht J, van Schoor J. Prevalence, classification and perception of allergic and nonallergic rhinitis in Belgium. Allergy. 2006;61(6):693-8.

2. Tran NP, Vickery J, Blaiss MS. Management of rhinitis: allergic and nonallergic. Allergy Asthma Immunol Res. 2011;3(3):148-56.

3. Brożek JL, Bousquet J, Agache I, Agarwal A, Bachert C, Bosnic-Anticevich $\mathrm{S}$, et al. Allergic Rhinitis and its Impact on Asthma (ARIA) guidelines-2016 revision. J Allergy Clin Immunol. 2017;140(4):950-8.

4. Wang Q, Lenham RK, Wang X, Li Y, Jiang M, Chen W, et al. A pilot study demonstrating the evidence for reflux disease in patients presenting with non-allergic rhinitis (NAR) - reflux disease in association with non-allergic rhinitis. Ann Esophagus. 2019:2:6.

5. El-Serag HB, Sweet S, Winchester CC, Dent J. Update on the epidemiology of gastro-oesophageal reflux disease: a systematic review. Gut. 2014;63:871-80.

6. Vakil N, van Zanten SN, Kahrilas P, Dent J, Jones R. Globale konsensusgruppe. The Montreal definition and classification of gastroesophageal reflux disease: a global evidence-based consensus. Am J Gastroenterol. 2006;101:1900.

7. Wong IWY, Omari TI, Myers JC, Rees G, Nair SB, Jamieson GG, et al. Nasopharyngeal pH monitoring in chronic sinusitis patients using a novel four channel probe. Laryngoscope. 2004;114(9):1582-5.

8. Phipps CD, Wood WE, Gibson WS, Cochran WJ. Gastroesophageal reflux contributing to chronic sinus disease in children: a prospective analysis. Arch Otolaryngol Head Neck Surg. 2000;126(7):831-6.

9. Bothwell MR, Parsons DS, Talbot A, Barbero GJ, Wilder B. Outcome of reflux therapy on pediatric chronic sinusitis. Otolaryngol Head Neck Surg. 1999;121(3):255-62.

10. Katle EJ, Hart H, Kjaergaard T, Kvaløy JT, Steinsvåg SK. Nose- and sinus-related quality of life and GERD. Eur Arch Otorhinolaryngol. 2012;269(1):121-5.

11. Loehrl TA, Samuels TL, Poetker DM, Toohill RJ, Blumin JH, Johnston N. The role of extraesophageal reflux in medically and surgically refractory rhinosinusitis. Laryngoscope. 2012;122(7):1425-30.

12. Chambers DW, Davis WE, Cook PR, Nishioka GJ, Rudman DT. Long-term outcome analysis of functional endoscopic sinus surgery: correlation of symptoms with endoscopic examination finding and potential prognostic variables. Laryngoscope. 1997;107(4):504-10.

13. Hanna BC, Wormald PJ. Gastroesophageal reflux and chronic rhinosinusitis. Curr Opin Otolaryngol Head Neck Surg. 2012;20(1):15-8.

14. Lupa M, DelGaudio JM. Evidence-based practice. Otolaryngol Clin N Am. 2012;45:983-92.

15. Flook EP, Kumar BN. Is there evidence to link acid reflux with chronic sinusitis or any nasal symptoms?A review of the evidence. Rhinology. 2011:49:11-6.

16. Bohnhorst I, Jawad S, Lange B, Kjeldsen J, Hansen JM, Kjeldsen AD. Prevalence of chronic rhinosinusitis in a population of patients with gastroesophageal reflux disease. Am J Rhinol Allergy. 2015;29(3):e70-4.

17. Lin YH, Chang TS, Yao YC, Li YC. Increased risk of chronic sinusitis in adults with gastroesophgeal reflux disease: a nationwide population-based cohort study. Medicine. 2015;94(39):e1642.

18. Caminha GP, Pizzichini E, Neto JFL, Hopkins C, Moreira JDS, Pizzichini MMM. Rhinosinusitis symptoms, smoking and COPD: prevalence and associations. Clin Otolaryngol. 2018;43(6):1560-5.

19. Mandolesi D, Schiavon P, loannou A, Mancini M, Cimatti MC, Azzaroli F, et al. Chronic non-allergic rhinitis with neutrophils is associated with higher acid exposure time: a pH-impedance monitoring study. Dig Liver Dis. 2020;52(4):414-9. 
20. Orlandi RR, Kingdom TT, Hwang PH, Smith TL, Alt JA, Baroody FM, et al. International consensus statement on allergy and rhinology: rhinosinusitis. Int Forum Allergy Rhinol. 2016;6(Suppl 1):S22-209.

21. Wise SK, Lin SY, Toskala E, Orlandi RR, Akdis CA, Alt JA, et al. International consensus statement on allergy and rhinology: allergic rhinitis. Int Forum Allergy Rhinol. 2018;8(2):108-352.

22. Schiöler L, Ruth M, Jõgi R, Gislason T, Storaas T, Janson C, et al. Nocturnal GERD — a risk factor for rhinitis/rhinosinusitis: the RHINE study. Allergy. 2015:70(6):697-702.

23. de Marco R, Accordini S, Antonicelli L, Bellia V, Bettin MD, Bombieri C, et al. The gene-environment interactions in respiratory diseases (GEIRD) project. Int Arch Allergy Immunol. 2010;152(3):255-63.

24. Agresti A. Categorical data analysis. New York, NY: John Wiley \& Sons; 1990.

25. Sella GCP, Tamashiro E, Anselmo-Lima WT, Valera FCP. Relation between chronic rhinosinusitis and gastroesophageal reflux in adults: systematic review. Braz J Otorhinolaryngol. 2017;83(3):356-63.

26. Katle EJ, Hatlebakk JG, Grimstad T, Kvaløy JT, Steinsvåg SK. Gastro-oesophageal reflux in patients with chronic rhinosinusitis investigated with multichannel impedance-pH monitoring. Rhinology. 2017:55:27-33.

27. Holma B, Lindegren M, Andersen JM. pH effects on ciliomotility and morphology of respiratory mucosa. Arch Environ Health. 1977;32:216-26.

28. Delehaye E, Dore MP, Bozzo C, Mameli L, Delitala G, Meloni F. Correlation between nasal mucociliary clearance time and gastroesophagea reflux disease: our experience on 50 patients. Auris Nasus Larynx. 2009;36(2):157-61.

29. Hait EJ, McDonald DR. Impact of gastroesophageal reflux disease on mucosal immunity and atopic disorders. Clin Rev Allergy Immunol. 2019;57(2):213-25.

30. Wong IWY, Rees G, Greiff L, Myers JC, Jamieson GG, Wormald PJ. Gastroesophageal reflux disease and chronic sinusitis: in search of an esophageal-nasal reflex. Am J Rhinol Allergy. 2010;24:255-9.

31. Kurtaran H, Uyar ME, Kasapoglu B, Turkay C, Yilmaz T, Akcay A, Kanbay M. Role of Helicobacter Pylori in pathogenesis of upper respiratory system diseases. J Nat Med Assoc. 2008;100(10):1224-30.

32. Koc C, Arikan OK, Atasoy P, Aksoy A. Prevalence of Helicobacter Pylori in patients with nasal polyps: a preliminary report. Laryngoscope. 2004;114(11):1941-4

33. Morinaka S, Ichimiya M, Nakamura H. Detection of Helicobacter Pylori in nasal and maxillary sinus specimens from patients with chronic sinusitis. Laryngoscope. 2003;113(9):1557-63.

\section{Publisher's Note}

Springer Nature remains neutral with regard to jurisdictional claims in published maps and institutional affiliations.
Ready to submit your research? Choose BMC and benefit from:

- fast, convenient online submission

- thorough peer review by experienced researchers in your field

- rapid publication on acceptance

- support for research data, including large and complex data types

- gold Open Access which fosters wider collaboration and increased citations

- maximum visibility for your research: over 100M website views per year

At BMC, research is always in progress.

Learn more biomedcentral.com/submissions 